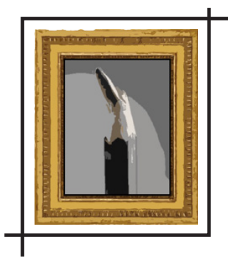

\title{
PROPOSTA DE UMA TAXONOMIA PARA OS PERSONAGENS GRÁFICOS
}

\section{Luiz Claudio Gonçalves Gomes*}

Resumo: Existe uma necessidade natural entre as pessoas de classificar ou categorizar as coisas. 0 presente trabalho propõe uma classificação taxonômica dos personagens gráficos e mascotes, sobretudo daqueles utilizados comercialmente. Confrontando os autores Clotilde Perez (2011) e Stephen Brown (2011), e por observação sistemática do universo de personagens encontrados (GOMES, 2008), estabelecemos distintas formas básicas de personagens, aqui nominados "as quatro morfologias arquetípicas". Para Martha García (2015), as mascotes podem ser classificadas em: animais, objetos ou coisas, letras desenhadas e a combinação destes. Fica evidente a incompletude na classificação desse autor, uma vez que, em seu artigo, não foram levados em conta os vegetais, que têm relevante participação no universo ali tratado. Na realidade, trata-se de uma obra incipiente a respeito do tema e somente a descrevemos aqui para ilustrar a escassez de referências nessa área. No entanto, Perez (2011, p. 80) trata da temática a partir de uma perspectiva científica desenvolvida em seu curso de pós-doutorado, fazendo por merecer um detalhamento cuidadoso com respeito ao tema que o inclui no âmbito da "produção de sentido das marcas" e é com essa obra, somada à obra de Brown (2011), que contrastaremos nossa análise pelo viés taxonômico. Acreditamos haver contemplado todas as necessidades de uma classificação completa para seres gráficos, personagens e mascotes.

Palavras-chave: Personagens. Mascotes. Taxonomia. Marca. Personificação.

\section{A ESTRUTURA TAXONÔMICA}

A taxonomia tem origem na biologia como uma ciência para ordenar organismos vivos em um sistema de classificação composto por uma hierarquia. Tempos mais tarde, o termo foi empregado em um sentido mais amplo, aplicando-se à classificação de coisas ou aos princí-

\footnotetext{
* Doutorando em Artes Visuais pela Universidade Federal do Rio de Janeiro (UFRJ). Mestre em Estudios Avanzados en Deseño pela Universitat de Barcelona e em Educação pela Universidade Federal Fluminense (UFF). Coordenador do Núcleo de Pesquisa em Artes, Design e Comunicação (Artdeco), professor do curso de Design Gráfico e do curso de Pós-Graduação em Gestão, Design e Marketing e coordenador de Imagem Institucional do Instituto Federal de Educação Tecnológica Fluminense. E-mail: luizclaudio.ub@gmail.com
} 
pios subjacentes da classificação. Quase tudo - objetos animados, objetos inanimados, lugares e eventos - pode ser classificado de acordo com algum esquema taxonômico.

A taxonomia é essencialmente uma organização mental que nos ajuda a comunicar e melhorar o pensamento. As pessoas adoram classificar coisas ao mesmo tempo que têm a necessidade reconhecê-las por categorias ou classes (WEINSCHENK, 2011).

0 designer Per Mollerup (1999) propõe em sua obra Marks of excellence uma estrutura taxonômica para as marcas comerciais. 0 autor determina que, para cumprir com seu propósito, a taxonomia de marca deve abarcar cinco funções:

- Uma classificação ideal deve consistir em classes que sejam distintas. Deve haver distinções rígidas entre as classes. A classificação de qualquer registro deve ser clara.

- As características nas quais a classificação está baseada devem ser usadas de modo consistente. Cada etapa da classificação deve estar baseada em um princípio de divisão.

- Classes coordenadas da taxonomia devem ser mutuamente excludentes. Não deve haver sobreposições entre as classes. Nenhum registro deve ser coberto por mais de uma classe.

- As classes coordenadas devem ser apuradas em conjunto. Devem cobrir todos os possíveis registros.

- As classes devem ser relevantes para o propósito da taxonomia.

Ainda assim, Mollerup (1999) reconhece que, por razões pragmáticas, essa taxonomia das marcas não é a ideal em alguns aspectos. Desenvolveu-se de uma maneira que inclui as falhas visíveis da distinção e da exclusão. Em seu livro, a primeira e a terceira regras foram violadas para satisfazer a quinta.

A taxonomia não tem limites claros entre todas as classes. As qualidades das marcas comerciais não são necessariamente claras e separadas, em geral possuem um contínuo. A taxonomia trabalha em relação à exclusividade e às qualidades isoladas das marcas. Na prática, as qualidades descritas nas classes não se excluem entre si, mas aparecem concorrentemente. É possivel ter qualidades de marca que pertençam a duas ou mais classes.

Uma das razões para aceitar esse estado de opções é que a taxonomia seria muito mais extensa e difícil de manejar se tentássemos cobrir todas as combinações possíveis das características das classes. Para fins analíticos, uma marca deve ser classificada de acordo com toda sua "dupla personalidade".

Para Mollerup (1999), o propósito da taxonomia não é produzir uma classificação que ponha fim à discussão e à crítica. É lançar luz sobre a natureza e a variedade de marcas e facilitar a análise da produção de significados sobre elas.

Trazendo a questão para o universo sígnico dos personagens, vemos pontos subjacentes mas também discordantes e que aqui os poremos com o objetivo de adotar um raciocínio paralelo e assim desenhar uma árvore taxonômica dos personagens. 
Foram encontrados apenas três autores que tratam exclusivamente de uma taxonomia dos personagens de marca: García (2015), Perez (2011) e Brown (2011). García (2015) classifica as mascotes em quatro grupos, Perez (2011) aponta para 18 ramos e inclui os "licenciados", enquanto Brown (2011) reduz a classificação em apenas três importantes grupos subdivididos em três categorias.

Para García (2015), as mascotes podem ser classificadas em: animais, objetos ou coisas, letras desenhadas e a combinação destes. Fica evidente a incompletude na classificação desse autor, uma vez que, em seu artigo, não foram levados em conta os vegetais, que têm relevante participação no universo ali tratado. Na realidade, trata-se de uma obra incipiente a respeito do tema e somente a descrevemos aqui par ilustrar a escassez de referências nessa área.

No entanto, Clotilde Perez (2011, p. 80) trata da temática a partir de uma perspectiva científica desenvolvida em seu curso de pós-doutorado, fazendo por merecer um detalhamento cuidadoso com respeito ao tema que o inclui no âmbito da "produção de sentido das marcas", e é com essa obra, somada à obra de Brown (2011), que contrastaremos nossa análise pelo viés taxonômico. Como contraponto, adotaremos a taxonomia de Mollerup (1999) para a aproximação com as classificações sobre as marcas comerciais.

\section{TAXONOMIA DE PERSONAGENS E MASCOTES SEGUNDO PEREZ}

Segundo a visão de Perez (2011, p. 84), os personagens formam um grupo constituído por "seres humanos, animais, mascotes e demais seres ficcionais que se encontram vinculados à marca". A principal vantagem de seu uso é o controle que a organização pode exercer sobre eles. Possuem maior capacidade de congruência e integração com a marca comercial, já que podem ser criados com objetivos claros e específicos.

A classe humanos é dividida por Perez (2011) em ficcionais, midiáticos e gráficos. A autora não distingue os personagens atores dos personagens gráficos nem os classifica como ficcionais. Perez (2011, p. 85) os define como "personagens que se constituíram a partir de pessoas comuns, que não tinham projeção midiática e que normalmente a repercussão foi decorrente da exposição como expressividade da marca". Para a autora, os personagens midiáticos são criados como escusa para ações de protesto, humoristicas e políticas, e cita como exemplo Rodolfo Chikilicuatre, um músico geek que cantava sempre com seu violão de brinquedo com muita irreverência e estilo extravagante. Os personagens gráficos são definidos como "representações humanas estáticas, muitas vezes com função de carimbo, selo ou símbolo agregado à identidade visual" (PEREZ, 2011, p. 87). Esses personagens se subdividem em corpóreos e metonímicos. Gráficos corpóreos correspondem aos personagens humanos parciais. Se, para a autora o personagem metonímico é estático como um selo, os personagens corpóreos dão margem a movimentos, o que lhes atribui o status de mascote. 
Figura 1 Taxonomia de personagens e mascotes

$$
\begin{aligned}
\text { Personalidades } & \left\{\begin{array}{l}
\text { Celebridades } \\
\text { Especialistas (experts) } \\
\text { Porta-voz }
\end{array}\right. \\
& \left(\text { Humanas } \left\{\begin{array} { l } 
{ \text { Ficcionais } } \\
{ \text { Midiáticas } } \\
{ \text { Gráficas } }
\end{array} \left\{\begin{array}{l}
\text { Corpóreas } \\
\text { Metonimicas }
\end{array}\right.\right.\right.
\end{aligned}
$$

Animais

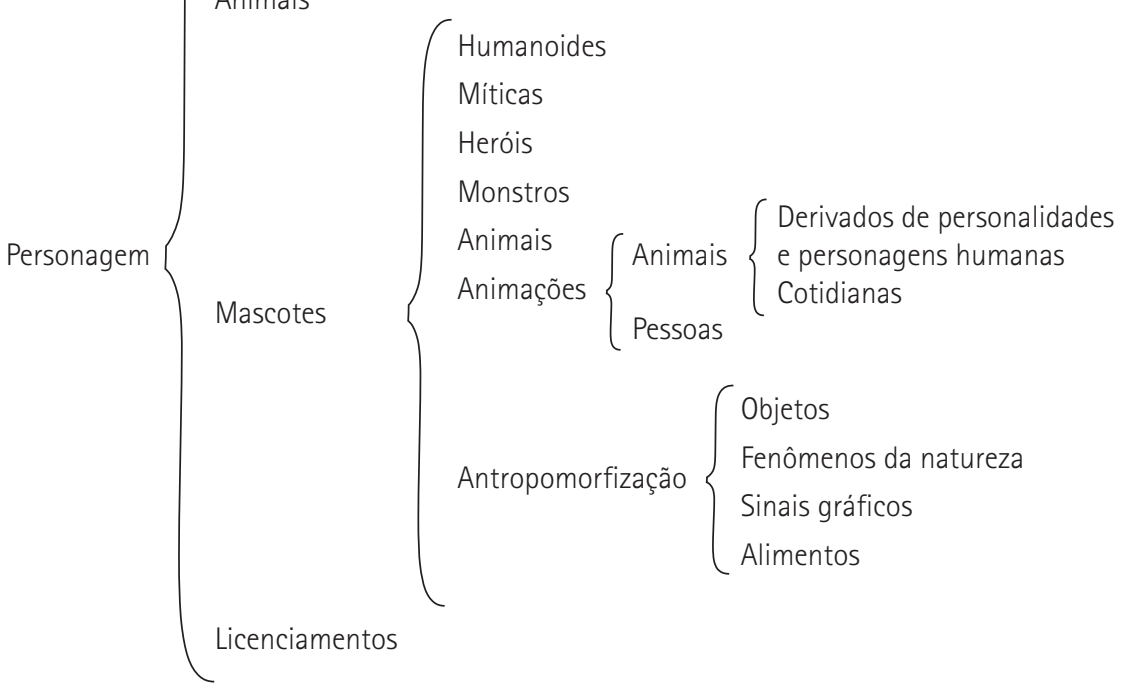

Fonte: Perez (2011, p. 81).

Animais é a classe de personagens que representam as marcas, "mas não manifestam fatos de vida, ou seja, são animais gráficos estáticos que funcionam como selo e, às vezes, como parte simbólica da identidade" visual (PEREZ, 2011, p. 8).

A classe mascotes é subdividida entre humanoides, miticas, heróis, monstros, animais, animações e antropomorfização. Perez (2011) os compreende como um agrupamento com grande diversidade de forma, design, estratégia e posicionamento. 0 traço sígnico comum em todas as segmentações é a manifestação de fatos de vida. À sua maneira, cada qual demonstra vitalidade e forte vinculação às marcas. Dentro de uma perspectiva semiótica, são expressões de marca, ou seja, capazes de acionar, individual e autonomamente, o universo sígnico construído pela marca (PEREZ, 2011, p. 90).

As mascotes humanoides identificam e distinguem as marcas e se apresentam como humanos, ainda que possam se travestir. As místicas são criadas a partir da mitologia e navegam pelo onírico e pela magia. 0 poder de transformação a que aludem sugere que elas podem associar-se a produtos de limpeza e alimentos. Segundo a autora, as mascotes do 
tipo heróis possuem ou sugerem superpoderes, enquanto as mascotes monstros são representações disformes de seres com vida, mas não guardam caracteristicas essencialmente humanas ou animais. Apesar das hibridações entre os universos humano, animal ou mitológico, as mascotes monstros comunicam muita afetividade e despertam sentimento de adesão. Segundo a compreensão de Perez (2011, p. 93), a classe de mascotes animais refere-se a um recurso de incorporação da marca a um ser não antropomorfizado: "As mascotes animais não são uma representação ou animação de animais, são os próprios animais expressos por meio de imagens fotográficas". Mascotes de animação se subdividem em animais e pessoas, mas com representação ficcional e habitualmente caricatas, hiperbólicas. Desse modo, as animações de animais configuram-se como desenhos animados antropomorfizados, geralmente domésticos e de fácil convivência. Por sua vez, as pessoas animadas referem-se às mascotes de desenhos animados de figuras humanas lúdicas e com forte dinamicidade.

Por fim, a autora descreve a classe das mascotes antropomorfizadas que está subdividida em objetos, fenômenos da natureza, sinais gráficos e alimentos. Entre os objetos antropomorfizados, ela classifica os próprios produtos ou suas respectivas embalagens nessa categoria. Sol, lua, fogo, vento, entre outros, são os elementos passiveis de se converter em mascotes inspiradas nos fenômenos naturais. Do mesmo modo, caracteres distintos e o próprio logotipo podem inspirar mascotes como sinais gráficos. Por último, os alimentos como leguminosas e cereais são fontes de vida passivel de antropomorfização para potencializar os efeitos de sentido de afetividade.

Uma última classe definida por Perez (2011) são os licenciados que é muito distinta das demais, principalmente por estabelecer uma relação central entre a organização e a marca, e, portanto, também com a outra organização, proprietária do personagem. As vantagens se ancoram no êxito que os personagens têm, e o vínculo deles com a marca certamente trará camadas de sentidos ligadas à modernização e atualização.

\section{TAXONOMIA DAS PERSONIFICAÇÕES DA MARCA SEGUNDO BROWN}

A prevalência da personificação é incontestável. Tanto é certo que uma tipologia das manifestações de marketing - a metáfora - pode ser uma proposta. Como mostra o esquema que ilustra a Figura 2, este compõe-se de três categorias básicas da personificação: antropomorfismo, em que ao produto ou à marca atribuem-se o nome e as características de um ser humano (Uncle Ben, Mr Tayto); zoomorfismo, em que o produto ou a marca estão alinhados com um selvagem ou domesticados animais (carro Jaguar, sabonete Dove); e teramorfismo, em que os atributos de uma criatura imaginária, sobrenatural ou prodigiosa, estendem-se aos bens ou serviços (Fairy Liquid, Monster Munch). Além dessas formas básicas da personificação, existem variações na natureza da relação figurativa entre a marca e 0 
ícone. Em alguns casos, a relação é metafórica, em que o nome da marca e a encarnação são uma e o mesmo (Mr Muscle, Tiger Beer). Em outros casos, é metonímica, em que a personificação é um aval mais que uma forma de realização da marca (Mr Peanut, Clydesdales Budweiser). Em outros casos, a relação é um símil (analogia), mais solta, a vinculação com associação de duração mais curta (como no caso de Pepsi ou L'Oreal, em que famosos "rostos da marca" são substituídos periodicamente) (BROWN, 2011).

Figura 2 Taxonomia das personificações da marca, segundo Brown (2011)

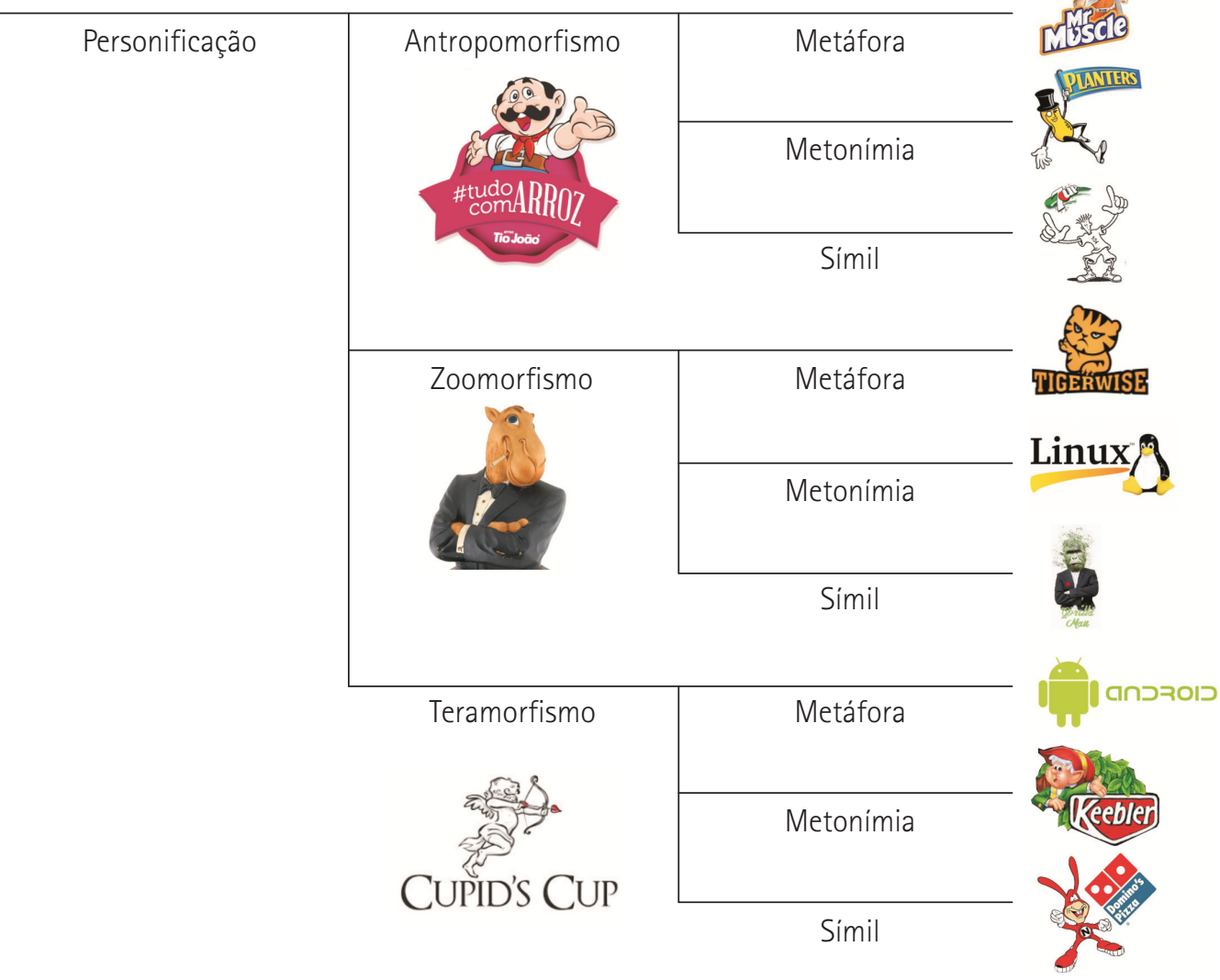

Fonte: Adaptada de Brown' (2011). 
Em seu conjunto, essas categorias especulativas compreendem uma classificação de nove células de personificações de marca, que dão uma ideia da linguagem figurada sob muitas e variadas formas de expressão. As categorias, é certo, são menos claras na prática do que são em teoria. Bibendum de Michelin, por exemplo, é um personagem tanto de antropomorfismo (figura humana reconhecivel) e teramorfismo (desenho animado composto por gigantes pneus). Ainda que sua relação com a marca seja metonímica (embaixadores em lugar da encarnação), o personagem é desenhado sobre uma base regular (como o "Running Bibendum" design da década de 1980), quase se aproximando da categoria símil (DARMON, 1997). 0 coelhinho de Energizer, do mesmo modo, oscila em algum lugar entre zoomorfismo e teramorfismo - já que os coelhos rosados são relativamente raros na natureza - e em algum lugar entre a metáfora e a metonimia, porque a mascote e o produto são independentes mas inseparáveis na mente de muitas pessoas. Existe uma dimensão temporal importante também, já que a relação entre o ícone da marca e a organização patrocinadora pode mudar através do tempo. Jolly Green Giant começou como porta-voz de teramórfico para o Valle de Minnesota Ganning Gompany, igual ao Monstro Honey de cereais para o café da manhã de Quaker, mas hoje em dia as empresas têm o nome de suas mascotes de marca sobre-humanas. As criaturas se apoderaram das empresas.

\section{TAXONOMIA DOS PERSONAGENS}

Ressaltamos que nossa investigação se pauta nos personagens gráficos, ou seja, personagens produzidos pela criação humana e representados sob determinados preceitos, estilos e técnicas gráficas. Incluem-se aí os desenhos feitos à mão por meio de lápis, canetas e tintas das mais variadas, do mesmo modo os que hoje, habitualmente, são finalizados por meio digital. Sendo assim, estão excluídos os personagens reais, como as celebridades e os astros da indústria cultural, ou mesmo outros autores humanos.

Nossa estrutura taxonômica está proposta em uma raiz com o substantivo "personagem" como origem conceitual deste trabalho investigativo. Desse modo, já podemos dividir o primeiro grupo de ramos com os conceitos polares entre "personagem gráfico" e personagem real ("não gráfico"), tal qual definidos anteriormente². Neste ponto, ressaltamos o conceito de "escala de iconicidade", que nos servirá para explicar a diferença que aqui definimos como "gráfico" e "não gráfico". Vejamos a Figura 3. As imagens são de um personagem conhecido mundialmente. Na sequência, o único que está excluído de nosso parâmetro de análise é o

2 - 0 referente usado por esta pesquisa é o que adota a World Intellectual Property Organization (Wipo) - que classifica o personagem nas seguintes tipologias básicas: os seres humanos de ficção ou os não humanos e as pessoas reais. Aqui os adotamos como "gráficos" e "não gráficos". 
primeiro, por tratar-se de uma fotografia (representação do real), enquanto os demais são representações artificiais do primeiro, portanto aqui definidos como "gráficos".

Figura 3 "Carlitos" em escala de iconicidade
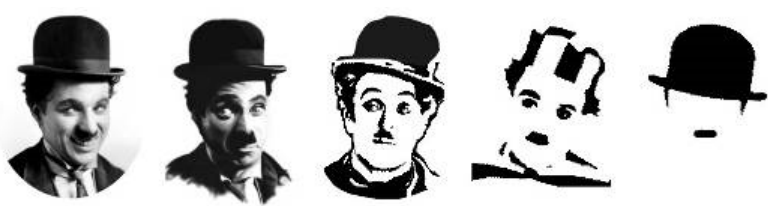

Fonte: Elaborada pelo autor.

Vale destacar que o grau de iconicidade não é suficiente para determinar um personagem "gráfico" ou "não gráfico". Podemos deduzir de antemão que uma fotografia tem grau máximo de iconicidade, mas uma ilustração hiper-realista também o tem. Portanto, o meio e a técnica de representação são o que conta.

Devemos ressaltar o âmbito "gráfico" como ilimitado e que permite transcender na relação de inúmeros personagens com formas e cores surpreendentes e inusitadas. Trata-se de um universo controlado pelas mãos dos ilustradores, designers e gestores de imagem gráfica. A concepção, o desenvolvimento e os passos desses personagens imaginários se estabelecem à luz das demandas de mercado e não se sujeitam a acidentes de percurso e de atos inesperados que mancham a imagem e a identificação visual de empresas e produtos. 0 mesmo não se pode dizer dos personagens reais quando muitos deles, não excepcionalmente, estão relacionados a notícias difamatórias.

A raiz de nossa estrutura bem poderia começar pelo conceito de "personagem gráfico", mas acreditamos ser importante aclarar o conceito de "personagem não gráfico" e a razão pela qual o descartamos em nosso estudo. Entendemos que optar pela raiz "personagem" de modo generalista seja mais didático e contribui para melhor elucidá-lo dentro desse universo. Entretanto, deixamos claro que somente os personagens gráficos foram delimitados como objetos de estudo no presente trabalho.

Temos observado que o personagem gráfico para caracterizar-se como tal deve possuir as características de personne e que membros, tronco e cabeça (por vezes, os dois últimos podem se misturar em determinadas configurações anatômicas) são componentes fundamentais para se constituir em ícone de identidade corporativa. Mas esse personagem pode ser morfologicamente humano, pode adquirir forma humanizada ou abstrata. 
Figura 4 As quatro morfologias arquetípicas ${ }^{3}$
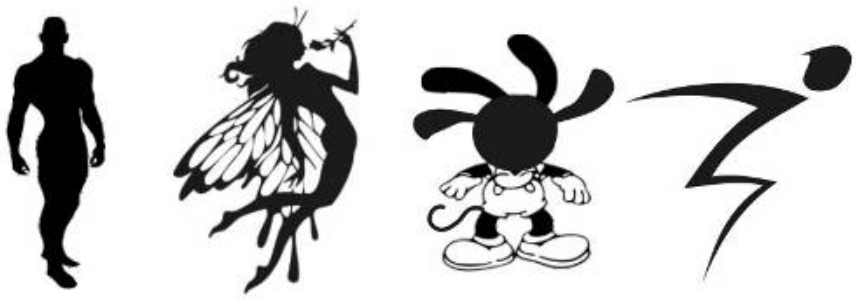

Fonte: Elaborada pelo autor.

0 passo seguinte é subdividir os personagens gráficos em quantas vezes julguemos necessário, respeitando as cinco funções propostas por Mollerup (1999), tanto quanto seja possível, para satisfazer nossa classificação.

Confrontando os autores citados e por observação sistemática (Gomes, 2008) ${ }^{4}$ do universo de personagens encontrados, chegamos à conclusão de que são quatro formas básicas que podem suprir essa classe intermediária. É o que aqui nominamos "as quatro morfologias arquetípicas". E assim definimos as quatro formas originais como: humano, extra-humano, antropomorfo e abstrato.

A taxonomia dos personagens é mostrada em forma de árvore na Figura 5. 0 tronco é o primeiro gênero, a classe em que se inicia a divisão. Os 11 ramos da direita são das espécies secundárias, as classes finais. No meio, estão os gêneros menores, as classes intermediárias. Entre os 11 ramos da direita, como dito anteriormente, excluímos a linha pontilhada referente aos personagens não gráficos, pelas razões já apresentadas.

Consideramos que seja suficiente subclassificar o personagem humano em real e comic/ caricato por acreditarmos que os dois conceitos abarcam o universo possivel da representação humana em sua morfologia universalizada.

Mas a forma humana pode sucumbir a mundos desconhecidos e oníricos. As lendas, a mitologia e a ficção são um campo rico para a criação de seres encantados e por vezes monstruosos. É o que aqui definimos como personagens extra-humanos e que subdividimos em mito e ficção científica. A mitologia mundial é frutífera para a apropriação de seres,

\footnotetext{
3 - Referem-se à morfologia dos descendentes. Vogler (2006, p. 49), influenciado pelo trabalho de Vladimir Propp, que observa a narração a partir da perspectiva das funções realizadas pelos personagens, sugere que os arquétipos são tomados como máscaras que os personagens de uma história possuem, utilizando-as de maneira temporal de acordo com a necessidade do progresso da trama. Outras perspectivas, também sugeridas por Vogler (2006), são: ver os arquétipos como facetas da personalidade do herói, as possibilidades (boas ou más) para o protagonista; entendê-los como a personificação das diferentes qualidades humanas.

4 - Trabalho desenvolvido e apresentado pelo autor no curso de doutorado Investigación en Diseño, para a obtenção do Diploma de Estudos Avançados (DEA), na Faculdade de Belas Artes, da Universidade de Barcelona. Na ocasião foram analisados 156 personagens imaginários. Atualmente esse rol já ultrapassa a 200 personagens.
} 
enquanto a ficção científica a cada dia proporciona um leque maior de opções para a criação, e talvez o mais emblemático tipo dessa classe sejam os robôs.

As formas antropomorfas são uma generalização das misturas possíveis entre os seres vivos, em que uma parcela humana há de existir. Mais humano, mais animal ou mais vegetal, o importante aqui é que a configuração do personagem sugira a presença humana em sua forma geral ou particular. Mas não somente a partir dos animais e dos vegetais é possível realizar desenhos antropomorfos de personagens e mascotes. Sendo assim, esgotamos todas as possibilidades para essa hibridação entre o humano e os demais reinos naturais, além de fenômenos naturais e objetos em geral (quase sempre o produto que representa ou sua embalagem).

Figura 5 Árvore taxonômica dos personagens

\begin{tabular}{|c|c|c|c|}
\hline \multirow[t]{10}{*}{$\begin{array}{l}\text { Personagem } \\
1\end{array}$} & \multirow[t]{10}{*}{$\begin{array}{l}\text { Gráfico } \\
1.1\end{array}$} & \multirow[t]{2}{*}{$\begin{array}{l}\text { Humano } \\
1.1 .1\end{array}$} & $\begin{array}{l}\text { Real } \\
1.1 .1 .1\end{array}$ \\
\hline & & & $\begin{array}{l}\text { Comic | Caricato } \\
\text { 1.1.1.2 }\end{array}$ \\
\hline & & \multirow[t]{2}{*}{$\begin{array}{l}\text { Extra-humano } \\
1.1 .2\end{array}$} & $\begin{array}{l}\text { Mítico } \\
1.1 .2 .1\end{array}$ \\
\hline & & & $\begin{array}{l}\text { Ficção científica } \\
1.1 .2 .2\end{array}$ \\
\hline & & \multirow[t]{5}{*}{$\begin{array}{l}\text { Antropomorfo } \\
1.1 .3\end{array}$} & $\begin{array}{l}\text { Objeto } \\
1.1 .3 .1\end{array}$ \\
\hline & & & $\begin{array}{l}\text { Vegetal } \\
1.1 .3 .2 \\
\end{array}$ \\
\hline & & & $\begin{array}{l}\text { Animal } \\
1.1 .3 .3\end{array}$ \\
\hline & & & $\begin{array}{l}\text { Mineral } \\
\text { 1.1.3.4 } \\
\end{array}$ \\
\hline & & & $\begin{array}{l}\text { Fenômeno natural } \\
\text { 1.1.3.5 }\end{array}$ \\
\hline & & $\begin{array}{l}\text { Abstrato } \\
1.1 .4\end{array}$ & \\
\hline
\end{tabular}

Não gráfico

1.2

Fonte: Elaborada pelo autor.

A abstração se opõe ao figurativo, portanto a última possibilidade de classe é o abstrato adotado quando já não existe possibilidade de enquadrar o personagem em nenhuma das classes figurativas anteriormente apresentadas. 


\section{CONSIDERAÇÕES FINAIS}

Desse modo, acreditamos contemplar todas as necessidades de uma classificação completa para os seres gráficos, personagens e mascotes, protagonistas do mundo sígnico das artes e dos produtos comerciais. 0 trabalho aqui apresentado pretendeu modestamente oferecer uma possibilidade coerente para satisfazer aqueles que pretendam classificar os personagens e torná-los reconhecidos por meio de classes.

\section{Taxonomy of graphic characters}

Abstract: People have a natural need to classify and categorize things. This paper proposes a taxonomic classification of graphic characters and mascots, mostly of those that have been used commercially. Contrasting authors Clotilde Perez (2011) and Stephen Brown (2011) and also by systematic looking at the universe of found characters (GOMES, 2008), we established different basic forms for characters, herein named "the four archetypical morphologies". For Martha García (2015), mascots can be classified in:animals, objects or things, letters drawn, and the combination of these. It is evident the incompleteness in the classification of this author since in his article did not take into account the vegetables, which have relevant participation in the universe there treated. In fact, it is an incipient work on the subject and we only describe it here to illustrate the scarcity of references in this area. However, Perez $(2011$, p. 80) deals with the subject from a scientific perspective developed in his postdoctoral course, deserving careful detail regarding the theme that includes it in the scope of "brands" and it is with this work, added to the work of Brown (2011), that we contrast our analysis from the taxonomic bias. As a conclusion, we believe having included all the needs for a thorough classification of graphic beings, characters and mascots.

Keywords: Characters. Mascots. Taxonomy. Brand. Personification.

\section{REFERÊNCIAS}

BROWN, S. It's alive inside! A note on the prevalence of personification. Irish Marketing Review, v. 21, n. 1-2, p. 3-11, 2011.

DARMON, O. One hundred years of Michelin Man. Paris: Editions Hoebeke, 1997.

GARCÍA, M. A. La mascota publicitaria como monstruo contemporáneo. Encuadre, v. 2, n. 11, p. 52-68, 2015.

GOMES, L. C. El personaje de marca como elemento renaciente en la identidad visual corporativa. 2008. Tesis (Doctorado en Diseño) - Universidad de Barcelona, Barcelona, 2008. 
MOLLERUP, P. Marks of excellence: the history and taxonomy of trademarks. London: Phaidon, 1999.

PEREZ, C. Mascotes: semiótica da vida imaginária. São Paulo: Cengage Learning, 2011.

VOGLER, C. A jornada do escritor: estruturas míticas para escritores. Rio de Janeiro: Nova Fronteira, 2006.

WEINSCHENK, S. Diseño inteligente: 100 cosas sobre la gente que cada diseñador necesita saber. Barcelona: Anaya Multimedia, 2011. 